\title{
INVESTIGATION OF ENERGY RESOURCES AND GAS DISCOVERIES IN THE EASTERN MEDITERRANEAN REGION: THE CASE OF PEOPLE'S EXPECTATIONS AND SOCIAL IMPACTS IN EGYPT
}

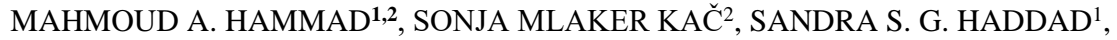 \\ HABIBA S. EL ROUBY ${ }^{1}$ \\ ${ }^{1}$ Arab Academy for Science, Technology and Maritime Transport/College of International \\ Transport and Logistics, Alexandria,Egypt,m.hammad@aast.edu, sandra.haddad@aast.edu, \\ habiba.roubi@aast.edu \\ ${ }^{2}$ University of Maribor/ Faculty of Logistics, Celje, Slovenia, e-mail: sonja.mlaker@um.si
}

\begin{abstract}
This study discusses the expected social impacts due to the recent offshore gas findings and development in the Eastern Mediterranean region on human communities in Alexandrian in the North of Egypt. A sample of 401 respondents of ordinary people who are living in the Alexandria governorate were sampled for the study using a convenience non-random sampling approach. The study showed most people are somewhat familiar with the ongoing gas discoveries in the Mediterranean Sea. The study also revealed that the people in Egypt have relatively high expectations from these gas discoveries. The ordinary people in Egypt expected that such discoveries of gas would have many positive and negative social impacts side by side. They expected severa social benefits of gas finds such as: the contribution to the diversification of the economy, infrastructural development, expanding social services, improvement of the standard of living, business and investment opportunities, employment.
\end{abstract}

Keywords: Oil and gas discoveries, people's expectations, social impacts

\section{INTRODUCTION}

Energy plays a vital role in the economy of every country and its importance can be seen in all aspects of our life (Ambituuni et al., 2015). Gas or natural gas is being used for several purposes such as heating energy, power or electricity, fuel for engines or transport fuel, and the chemical feedstock as well as an energy source for making a commodity that needs large energy requirements in its manufacture (Thomas and Dawe, 2003). Egypt is considered one of the important players in the Mediterranean region. It is the largest non-OPEC (Organization of the Petroleum Exporting Countries) oil producer in Africa (Hegazy, 2015) as well as it owns one of the most highly developed liquefied natural gas (LNG) and export infrastructures in the Eastern Mediterranean (Tsakiris et al., 2018). This study aims to identify the potential positive and negative social implications on the Egyptians' life as a result of gas findings in the Mediterranean Sea. Thus, the study is structured around three main objectives, namely: 1) to highlight the main social impacts of gas explorations on Egyptians, 2) to identify the social benefits of gas exploration on the Egyptian people, 3) to identify the social drawbacks/challenges of gas exploration on the Egyptian people.

\section{THEORETICAL BACKGROUND}

In order to realize the objectives of this study literature was reviewed and the three following theories, on the impact of gas explorations on social, economic and political implications, were studied. 


\section{Resource Curse Theory}

According to Adusah-Karikari (2012) resource curse theory aims at explaining the correlation between the exploitation of natural resources in the social, economic and political implications for the nations that host them. The theory posits that countries endowed with natural resources, like fossil fuels and minerals, are more likely to experience poor development outcomes because of underlying political and institutional issues, such as authoritarianism and neo-patrimonial and rentier politics.

\section{Dutch Disease}

Dutch disease is a term coined after the negative effects of the North Sea oil discoveries in the Netherlands (1959) (Meadors, 2013; Tadeo, 2016) and it explains the loss of competitiveness in the non-resource sectors (non-booming goods) through the eminent appreciation of the exchange rate (Boughanem, 2014; Mahbob, 2017; Mawejje, 2019; Swilling, 2019) and switch of capital and labor to the booming mineral sector.

\section{Gas Discoveries and Citizens' Expectations}

According to Bategeka et al. (2008), citizens' expectation exists in different forms and may have different orientations whether positive or negative. Likewise, in the case of oil and gas discovery, the positive expectations are represented the real hopes that the precious resources will deliver considerable social, economic and infrastructural improvement.

\section{Social Impacts of Gas Exploitation}

Akakpo (2015) defines social impacts as the changes occur in communities or to individuals as a result of an externally-induced change, result in changing people live, work, play, relate to one another, organize to meet their needs, and generally cope as members of society. These social impacts are both negative and positive.

The following section will present the research methodology by which the aim of the study shall be realized.

\section{MATERIAL AND METHODS}

\section{Population and Sample}

The target population is the people who live in Alexandria governorate, Egypt and they were all the strata of society of Alexandria. In determining the sample- frame, the basic criterion was people who are only living in Alexandria. According to the Central Agency for Public Mobilization and Statistics (CAPMAS) and official reports, the total number of populations in Alexandria is about 5,380,000. Out of the target population, a sample size of minimum 384 respondents was selected to answer the questionnaires using a convenience non-random or non-probability sampling method.

\section{Data Collection and Analysis}

The quantitative approach was applied in the study; this is through conducting structured questionnaires in order to collect the primary data. The questionnaire was divided into two sections: first section, the level of awareness and the expectations of Egyptian citizens about the research topic and the role of the state to manage and control gas resources were measured. The construct of this section was adapted from the previous works of Paulson E. 
Tadeo (2016), Choumert-Nkolo (2018), Omar (2018). Second section contains of two subsections: Firstly, part one reflected the expected social benefits from natural gas explorations in the Mediterranean Sea on Egyptian people's life. Secondly, part two measured the prospective social challenges on the ordinary people in Egypt from natural gas explorations in the Mediterranean Sea. The second section was measured by using a seven-point Likert Scale anchored from 1= strongly disagree to $7=$ strongly agree. The construct of the second section was adapted from previous literature (Akakpo, 2015; Omar, 2018). The questionnaire-collected data were coded and analyzed using the statistical package for social sciences (SPSS) software, version 25.

\section{DISCUSSION}

\section{Perceptions and Expectations of the Respondents from Gas Operations and Discoveries}

Regarding the level of awareness, familiarity and the expectations of Egyptian citizens about gas resources and discoveries in the Mediterranean Sea. The results show that about $17 \%$ of the respondents have broad knowledge about these gas discoveries, but, most of them have average knowledge with $64 \%$, and $37 \%$ with limited knowledge. The optimists of the Egyptians see that there would be significant and positive effects on Egypt after the latest gas discoveries at $(84 \%)$, while a few of pessimists argue that these discoveries negative effects at (4\%), and the rest (12\%) said that no effect or change would happen at all. Nevertheless, $69 \%$ of them strongly support these gas explorations, $29 \%$ are neutral, and the opponents represent 2\%. This is because almost of people in Egypt (82\%) believe that gas resources are boon and gift from God, not indignation or curse. From their point of view, $35 \%$ of the Egyptians expected that the revenues or returns resulting from the explorations of gas in the Mediterranean would be "distributed evenly/equally", while $30 \%$ see that it may distribute according to "the population density", and "the distribution to the poor and poorest regions" was predicted by $27 \%$, finally "distribution to the areas where gas was discovered" at $8 \%$. Moreover, the respondents expected that the main sector in which such revenues should be invested or spent on is "education" with the highest answer (49\%), followed respectively by living standards $(21 \%)$, health services (10\%), economic development $(8 \%)$, infrastructure $(6 \%)$, national security $(3 \%)$, saving gas revenues $(2 \%)$, while, the least answer was "environment protection" as no one has chosen it. Furthermore, the ordinary people in Egypt expect that the Mediterranean gas may create some developments and improvements in many fields of their life. In which they respectively prioritized these improvements as follows; living standards or welfare, employment opportunities, healthcare service, infrastructure, social support (symbiosis), educational opportunities, the subsidy of goods or services, and public security by $(37 \%),(18 \%),(13 \%)$, $(11 \%),(9 \%),(6 \%),(2 \%)$, and $(2 \%)$. Hence, $37 \%$ agree that it will increase the standard of living and luxury level as the highest answer, whereas, the least answer was both support for goods or services and public security at $(2 \%)$.

\section{Level of State Involvement}

On the other hand, concerning the role and involvement of the Egyptian state in managing and controlling natural resources like oil and gas, about $61 \%$ of respondents see that the state has effective involvement and plays an essential role in managing such resources, while 20\% see the opposite, and 19\% don't have an idea. Although most of them expect that the state or government has the ability to manage and govern the revenue generated from new discoveries of gas in a "somewhat good" way at $(63 \%)$, "good" with $(27 \%)$ and "bad" way at $(10 \%)$. Additionally, respondents disagree that developing 
natural gas resources in Egypt will not lose the country's competitiveness in other sectors (non-gas related sectors) such as agriculture, services and manufacturing by (58\%), while $(19 \%)$ agree upon this.

\section{The Social Perceptions and Positive Social Impacts of the Mediterranean Gas Discoveries}

It could be observed that the majority of the sample anticipates achieving major positive effects on all social levels from gas exploration and in high degrees. Also, it was noted that the diversification of the economy had the most agreed answer with $(90 \%)$, while, the least answer is freeing the state from dependence on donors with (78\%).

\section{The Drawbacks and Negative Social Impacts of the Mediterranean Gas Discoveries}

The increased cost of living and increase in prices of goods and materials had the most agreed expectation with $(73 \%)$, whereas, the lowest expected impact is the wars and conflicts whether internal or external $(57 \%)$.

\section{Further Inferential Analyses Using Tests of Differences (T-test and ANOVA)}

Table 1. T-test for differences according to employment sector, gender and family position

\begin{tabular}{lllllll}
\hline & \multicolumn{2}{l}{ Level of awareness } & \multicolumn{2}{l}{ Social benefits } & \multicolumn{2}{l}{ Social challenges } \\
\hline 1. Gender & Male & Female & Male & Female & Male & Female \\
& $\mathrm{N}=263$ & $\mathrm{~N}=138$ & $\mathrm{~N}=263$ & $\mathrm{~N}=138$ & $\mathrm{~N}=263$ & $\mathrm{~N}=138$ \\
Mean & 2.5399 & 2.1957 & 5.6236 & 6.1087 & 3.0304 & 2.7174 \\
P-value & $\mathbf{. 0 0 0}$ & & $\mathbf{. 0 0 0}$ & & $\mathbf{. 5 9 1}$ & \\
2. You are an employee? & Gov. & private & Gov. & private & Gov. & private \\
& sector & sector & sector & sector & sector & sector \\
& $\mathrm{N}=20$ & $\mathrm{~N}=381$ & $\mathrm{~N}=20$ & $\mathrm{~N}=381$ & $\mathrm{~N}=20$ & $\mathrm{~N}=381$ \\
Mean & 2.2500 & 2.4304 & 6.2500 & 5.7664 & 2.2500 & 2.9580 \\
P-value & $\mathbf{0 0 0}$ & & $\mathbf{. 0 1 9}$ & & $\mathbf{. 0 1 3}$ & \\
3. Are you the head of the & $\mathrm{Yes}$ & $\mathrm{No}$ & $\mathrm{Yes}$ & $\mathrm{No}$ & $\mathrm{Yes}$ & $\mathrm{No}$ \\
family? & $\mathrm{N}=211$ & $\mathrm{~N}=190$ & $\mathrm{~N}=211$ & $\mathrm{~N}=190$ & $\mathrm{~N}=211$ & $\mathrm{~N}=190$ \\
Mean & 2.4929 & 2.3421 & 5.7299 & 5.8579 & 3.1327 & 2.6895 \\
P-value & $\mathbf{. 0 0 0}$ & & $\mathbf{. 0 4 6}$ & & $\mathbf{. 0 0 3}$ & \\
\hline
\end{tabular}

Table 1 shows in social challenges an insignificant difference with different gender groups, as the corresponding p-value is greater than 0.05 . Also, there is a significant difference in awareness level and social benefits and challenges since the corresponding $\mathrm{p}$-values are less than 0.05 .

Table 2. ANOVA Test for educational level

\begin{tabular}{cccccccc}
\hline \multirow{2}{*}{ Educational level } & \multirow{2}{*}{$\mathrm{N}$} & \multicolumn{2}{c}{ Level of awareness } & \multicolumn{2}{c}{ Social benefits } & \multicolumn{2}{c}{ Social challenges } \\
& & mean & P-value & mean & P-value & mean & P-value \\
\hline Primary & 6 & 3.0000 & & 7.0000 & & 1.0000 & \\
High school & 34 & 2.1471 & & 5.8529 & & 3.1176 & \\
University degree & 244 & 2.4713 & & 5.6926 & .001 & 3.0369 & .008 \\
Post graduate & 80 & 2.5375 & .000 & 5.6750 & & 2.8625 & \\
Nothing & 37 & 2.0000 & & 6.4324 & & 2.4324 & \\
Total & 401 & 2.4214 & & 5.7905 & & 2.9227 & \\
\hline
\end{tabular}


Table 2 demonstrated a significant difference in awareness level and social benefits and challenges because the corresponding p-values are all less than 0.05.

Table 3. ANOVA Test for differences according to job or social statuses

\begin{tabular}{cccccccc}
\hline \multirow{2}{*}{ Job/social status } & \multirow{2}{*}{$\mathrm{N}$} & \multicolumn{2}{c}{ Level of awareness } & \multicolumn{2}{c}{ Social benefits } & \multicolumn{2}{c}{ Social challenges } \\
& & mean & P-value & mean & P-value & mean & P-value \\
\hline Employee & 194 & 2.597 & & 5.582 & & 2.886 & \\
Unemployed & 13 & 2.38 & & 6.000 & & 2.846 & \\
Retired & 39 & 2.256 & & 5.179 & & 3.974 & \\
Student & 67 & 2.358 & .000 & 6.089 & .001 & 2.895 & .008 \\
House wife & 80 & 2.175 & & 6.287 & & 2.725 & \\
Unable to work & 8 & 2.000 & & 6.000 & & 1.000 & \\
Total & 401 & 2.421 & & 5.790 & & 2.9227 & \\
\hline
\end{tabular}

The table proves that there is a significant difference in the level of awareness as well as social benefits and challenges. i.e. the corresponding p-values are all less than 0.05 .

Table 4. ANOVA Test for differences according to level of social welfare

\begin{tabular}{cccccccc}
\hline Level of social & \multirow{2}{*}{$\mathrm{N}$} & \multicolumn{2}{c}{ Level of awareness } & \multicolumn{2}{c}{ Social benefits } & \multicolumn{2}{c}{ Social challenges } \\
welfare & & mean & P-value & mean & P-value & mean & P-value \\
\hline Poor family & 42 & 2.00 & & 6.30 & & 2.45 & \\
Fairly average family & 349 & 2.46 & .000 & 5.73 & .015 & 3.03 & .000 \\
Rich family & 10 & 2.50 & & 5.50 & & 1.00 & \\
Total & 401 & 2.42 & & 5.79 & & 2.92 & \\
\hline
\end{tabular}

Table 4 shows that there is a significant difference of level of awareness, social benefits and social challenges, as the corresponding p-values are all less than 0.05 .

Table 5. ANOVA test for differences according to the main source of income

\begin{tabular}{|c|c|c|c|c|c|c|c|}
\hline \multirow{2}{*}{$\begin{array}{c}\text { The main source of } \\
\text { income }\end{array}$} & \multirow{2}{*}{$\mathrm{N}$} & \multicolumn{2}{|c|}{ Level of awareness } & \multicolumn{2}{|c|}{ Social benefits } & \multicolumn{2}{|c|}{ Social challenges } \\
\hline & & mean & $\mathrm{P}$-value & mean & P-value & mean & $\mathrm{P}$-value \\
\hline Salary & 209 & 2.42 & & 5.99 & & 2.86 & \\
\hline Bank interest & 5 & 2.00 & & 4.00 & & 1.00 & \\
\hline Pension (retirement) & 92 & 2.48 & & 5.06 & & 3.73 & \\
\hline $\begin{array}{l}\text { Income through the } \\
\text { business }\end{array}$ & 31 & 2.58 & .029 & 5.32 & .000 & 3.35 & .000 \\
\hline $\begin{array}{l}\text { Income source } \\
\text { through a property }\end{array}$ & 13 & 2.38 & & 7.00 & & 1.61 & \\
\hline Another source & 51 & 2.25 & & 6.43 & & 1.94 & \\
\hline Total & 401 & 2.42 & & 5.79 & & 2.92 & \\
\hline
\end{tabular}

At the end, ANOVA test for the difference in research variables according to different groups of the main source of income demonstrated that there is a significant difference in level of awareness, social benefits and social challenges, as the corresponding p-values are all less than 0.05 . 


\section{CONCLUSION}

This study assessed the expectations of the ordinary people in Egypt, and also examined the level of their awareness regarding recent gas discoveries in the Mediterranean region. The study used the questionnaires to examine the expected social opportunities and risks offered by the discovery of natural gas in Egypt's Alexandria governorate. The paper argued that the discovery of gas is followed by both positive and negative impacts on the social level. The expected positive impacts from gas discoveries in the Mediterranean from Egyptians' point of view could include; the contribution to the diversification of the economy, infrastructural development, expanding social services, improvement of the standard of living, business and investment opportunities, employment. Whereas, the negative social impacts might include; high cost of living, social vices, corruption, inequality, and wars. Nevertheless, the expected rates of occurrence of the positive impacts are higher than the frequents of the occurrence of the negative impacts. But that is not all, concerning the role and involvement of the Egyptian state in managing and controlling oil and gas resources, most of people see that the state has effective involvement and plays an essential role in managing such resources. Also, the majority of them expect that the government is fairly has the ability to manage and govern the revenue generated from new discoveries of gas, as well as these new gas resources will not lose the country's competitiveness in other sectors.

\section{REFERENCES}

Adusah-Karikari, A. (2012), "Black gold in Ghana: Changing Livelihoods for Women in Communities Affected by Oil Production", The Extractive Industries and Society, 2, 24-32, https://doi.org/10.1016/j.exis.2014.10.006.

Ambituuni, A., Amezaga, J. and Emeseh, E. (2015), "Analysis of Safety and Environmental Regulations for Downstream Petroleum Industry Operations in Nigeria: Problems and Prospects", Environmental Development, 9, 43-60, https://doi.org/10.1016/j.envdev.2013.12.002.

Bategeka, L., Kiiza, J. and Ssewanyana, S. (2008), "Oil Discovery in Uganda: Managing Expectations", Economic Policy Reseach Centre and Makerere University.

Boughanem, L.N. (2014), "The Curse of Natural Resources: A Vulnerability Assessment for Lebanon", Master's Thesis, American University of Beirut.

Hegazy, K. (2015), "Egypt's Energy Sector: Regional Cooperation Outlook and Prospects of Furthering Engagement with the Energy Charter", Brussels, Belgium, Energy Charter Secretariat.

Mahbob, M. (2017), “The Impact of the Oil Sector and Political Conflicts on the Libyan Economy”, Master's Thesis, Western Illinois University.

Mawejje, J. (2019), “The Oil Discovery in Uganda's Albertine Region: Local Expectations, Involvement, and Impacts", The Extractive Industries and Society, 6, 129-135, https://doi.org/10.1016/j.exis.2018.09.007.

Meadors, L. (2013), "Israel's Newfound Petroleum Wealth: A Critique of the "Resource Curse", Syracuse University Honors Program Capstone Projects (37), Syracuse University.

Swilling, R.A. (2019), "Investigating Sino-Africa relations: Exploring Investment and Governance regimes in the Sino-Ugandan Oil relations", Master's Thesis, Stellenbosch University.

Tadeo, P.E. (2016), “A Comparative Study of Oil Resource Management in Norway and Nigeria: Lessons for Kenya", Master's Thesis, University of Nairobi.

Thomas, S. and Dawe, R.A. (2003), "Review of Ways to Transport Natural Gas energy from Countries Which Do Not Need the Gas for Domestic Use”, Energy, 2003(28), 1461-1477, https://doi.org/10.1016/S03605442(03)00124-5.

Tsakiris, T., Ulgen, S. and Han, A.K. (2018), "Gas Developments in the Eastern Mediterranean: Trigger or Obstacle for EU-Turkey Cooperation?”, FEUTURE Online Paper No. 22, W. Wessels and N. Tocci, FEUTURE. 